\title{
Neurodevelopmental Outcomes of Moderate-to-Late Preterm Infants
}

Yun Sung Nam, MD, Ju Sun Heo, MD, Jung Hye Byeon, MD, PhD, and Eun Hee Lee, MD

Department of Pediatrics, Korea University College of Medicine, Seoul, Korea

\section{ABSTRACT}

Purpose: Preterm infants are known to be at a risk of neurodevelopmental delay; however, limited data are available on the outcomes of moderate-to-late preterm (MLPT) infants (born at 32 to 36 weeks' gestation). The Korean Developmental Screening Test (K-DST) for infants and children is a recently designed screening test for Korean infants and children. The current study aimed to evaluate the neurodevelopmental outcomes of MLPT infants and investigate the risk factors associated with neurodevelopmental delay.

Methods: A total of 119 MLPT infants admitted to a neonatal intensive care unit (NICU) of a tertiary hospital in Korea were enrolled. The infants were assessed during two follow-up periods (first: 16 to 24 months of corrected age; second: 24 to 41 months of corrected age). The perinatal factors in the NICU that were associated with delayed development were analyzed.

Results: In all sections of the K-DST, the proportion of infants with developmental delay was higher in the second period (5.6\% to $9.3 \%$ ) than in the first period ( $0.9 \%$ to $5.4 \%$ ). A total of $10 \%$ to $17 \%$ of the infants presented with persistent delay throughout the two periods based on five sections of the K-DST. Male sex, oxygen therapy duration, and younger maternal age were the risk factors affecting at least one section during the second period.

Conclusion: MLPT infants showed greater developmental delay than the general infant population. Considering that early intervention is important for good long. term outcomes, close observation of male MLPT infants and MLPT infants who received oxygen therapy is warranted.

Key Words: Child development; Infant, premature; Korea

\section{INTRODUCTION}

Moderate-to-late preterm (MLPT) infants are defined as infants born between the gestational age of 32 and 36 weeks, and they comprise up to $90 \%$ of all 15 million premature infants born annually worldwide ${ }^{1,2}$. Until recently, they were called "near-term" infants and were
Received: 17 May 2020

Revised: 31 August 2020

Accepted: 1 September 2020

Correspondence to: Eun Hee Lee, MD Department of Pediatrics, Korea University College of Medicine, 73 Goryeo dae-ro, Seongbuk-gu, Seoul 02841, Korea

Tel: +82-2-920-5090

Fax: +82-2-922-7476

E-mail:neoleeeh@gmail.com

Copyright(c)

By Korean Society of Neonatology.

All right reserved.

This is an Open-Access article distributed under the terms of the Creative Commons At tribution Non-Commercial License (http:// creativecommons.org/licenses/by-nc/4.0), which permits unrestricted non-commercial use, distribution, and reproduction in any medium, provided the original work is pro perly cited. 
expected to have a similar prognosis to term infants. However, an increasing number of reports have indicated that MLPT infants show higher risks of mortality, morbidity, and neurodevelopmental delay than full-term infants ${ }^{3-5)}$. Considering that early in tervention is vital for future neurodevelopmental prognosis early identification and assessment of neurodevelopmental delay in MLPT infants is crucial ${ }^{6,7)}$.

The Korean Developmental Screening Test (K-DST) for infants and children is a recently developed screening test in the form of a questionnaire. TheK-DST has 20 different types of questionnaires, and each questionnaire applies to different ages (4 to 71 months). Each K-DST questionnaire is classified into six different sections: gross motor, fine motor, cognition, communication, social interaction, and self-control (the self-control section is included from the 18-month questionnaire onward). An examiner scores the test on the basis of the responses, and the result of the K-DST is classified into four categories: further evaluation, follow-up test required, peer level, and high level ${ }^{8)}$. In a recent report using this test, the K-DST was proved to be an appropriate screening test for neurodevelopmental delay in comparison with other diagnostic tests for neurodevelopmental disorders, and infants classified into the "further evaluation" category (those who scored below -2 standard deviation) accounted for $1.5 \%$ to $3 \%$ of the general infant population ${ }^{9}$. To date, most studies on neurodevelopment in preterm infants have focused on infants with a very low birth weight (VLBW $)^{10-13)}$. Moreover, only a few follow-up studies on MLPT infants in Korea have been published ${ }^{14)}$. The current study aimed to evaluate the neurodevelopmental outcomes of MLPT infants using the K-DST and to investigate the relevant risk factors associated with delayed neurodevelopmental outcomes.

\section{MATERIALS AND METHODS}

\section{Study population}

In this retrospective study, the medical charts of infants born at 32 to 36 weeks of gestation and admitted to the Korea University Anam Hospital neonatal intensive care unit (NICU) from January 2013 to June 2017 were reviewed. Infants who did not re ceive appropriate follow-up care or were not administered the scheduled K-DST were excluded from this study.

\section{Study design}

All infants received regular follow-up care at an outpatient clinic after discharge from the NICU. The parents or guardians were asked to respond to the K-DST questionnaire from 16 to 41 months of corrected age of the infant. The results of the K-DST were analyzed during two follow-up periods: from 16 to 24 months of corrected age (first follow-up period) and from 24 to 41 months of corrected age (second follow-up period). The first version of the K-DST questionnaire, which has been superseded by the 2019 revised version, was used in this study. In the clinic, infants categorized into the "further evaluation" group were re commended to undergo further neurodevelopmental evalua tions, such as Bayley Scales of Infant Development, Sequenced Language Scale for Infants, and brain magnetic resonance ima ging (MRI). Appropriate interventions were recommended for infants diagnosed with developmental disabilities.

The results for the six sections were investigated at each followup period, and a subgroup analysis was performed according to gestational age. In infants with results for both follow-up periods, whether the neurodevelopmental delay was persistent or not was additionally investigated.

To identify the potential early postnatal risk factors affecting delayed neurodevelopmental outcomes, infants in the "further evaluation" and "follow-up test required" categories were included in the "delayed group," whereas those in the "peer level" and high level" categories were considered the "normal group." The characteristics during admission to the NICU of the delayed group and the normal group at each follow-up period were analyzed. The variables of neonatal characteristics were gestational age; birth weight; sex; major morbidities including respiratory distress syndrome requiring surfactant therapy, bronchopulmonary dys plasia, necrotizing enterocolitis (above stage II in the modified Bell's criteria), retinopathy of prematurity of any stage, patent ductus arteriosus with surgical or medical intervention, cultureproven sepsis, intraventricular hemorrhage of any grade, periventricular leukomalacia, and hypoglycemia; duration of admission; and duration of oxygen therapy including mechanical ventilation, noninvasive ventilation, and oxygen inhalation through nasal prongs. The variables of maternal characteristics were maternal age and maternal morbidities including preeclampsia, gestational diabetes mellitus, hypothyroidism, and oligohydramnios.

\section{Statistical analysis}

The differences in the results of the K-DST according to the different gestational ages were analyzed using logistic regression. Categorical variables were compared between the groups using 
the chi-square test or Fisher's exact test. Independent $t$-test or Mann-Whitney test was used for comparing continuous variables. The level of significance was set at $P<0.05$. IBM SPSS Statistics version 22.0 (IBM Co., Armonk, NY, USA) was used for data processing.

\section{RESULTS}

\section{Study population}

A total of 385 MLPT infants were admitted to the NICU during the study period. Of these, 231 infants had no available followup data after 16 months of corrected age and 35 infants were not administered the K-DST, although they continued their followup visits. Therefore, a total of 119 infants were finally included in the analysis.

Of the total study population of 119 infants, 113 infants were administered the K-DST during the first follow-up period (16 to 24 months of corrected age) and 54 infants were administered the K-DST during the second period (24 to 41 months of corrected age) (Figure 1). During the first follow-up period, there were 28

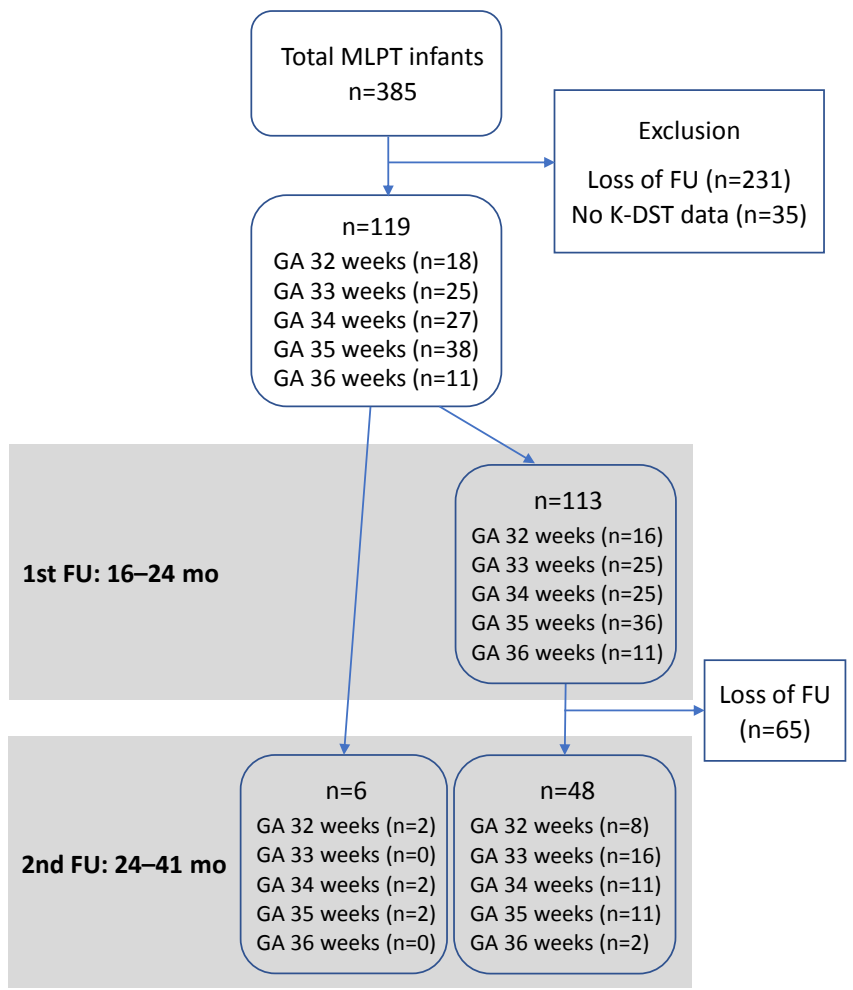

Figure 1. Flow of participants. Abbreviations: MLPT, moderateto-late preterm; FU, follow-up; K-DST, Korean Developmental Screening Test; GA, gestational age. infants with a corrected age of 16 to 17 months, 59 infants with a corrected age of 18 to 19 months, 16 infants with a corrected age of 20 to 21 months, and 10 infants with a corrected age of 22 to 23 months. Of the 113 infants who were administered the K-DST in the first follow-up period, 48 infants (42\%) were re-administered the K-DST during the second follow-up period. Six infants without a follow-up visit during the first follow-up period were first administered the K-DST during the second follow-up period. During the second follow-up period, there were 39 infants with a corrected age of 24 to 26 months, 11 infants with a corrected age of 27 to 29 months, two infants with a corrected age of 30 to 32 months, one infant with a corrected age of 33 to 35 months, and one infant with a corrected age of 36 to 41 months.

\section{Frequencies of delayed development}

The proportion of infants in the "further evaluation" group ranged from $0.9 \%$ to $5.4 \%$ during the first follow-up period and from $5.6 \%$ to $9.3 \%$ during the second follow-up period (Table 1). The proportion of infants in the "follow-up test required" group ranged from $17.7 \%$ to $21.2 \%$ during the first follow-up period and from $9.3 \%$ to $24.1 \%$ during the second follow-up period. The proportion of infants in the delayed group (infants in the "further evaluation" and "follow-up test required" categories) ranged from $21.3 \%$ to $26.6 \%$ during the first follow-up period. The highest proportion of MLPT infants with delayed development was associated with the communication section (26.6\%) followed by the social interaction section (25.6\%) of the K-DST. During the second follow-up period, the proportion of infants in the delayed group ranged from $18.6 \%$ to $29.7 \%$, and the highest proportion of MLPT infants with delayed development was associated was the fine motor section (29.7\%) followed by the social interaction section $(27.8 \%)$ of the K-DST.

We analyzed the proportion of infants in the delayed group according to gestational age. No significant difference was iden tified in the proportion of infants in the delayed group according to gestational age.

Ten infants underwent further neurodevelopmental evaluation, including six infants who underwent brain MRI. These six infants were diagnosed with tuberous sclerosis, bacterial meningitis, and cerebral palsy. In addition, seven infants underwent interventions such as speech therapy, play therapy, and physical therapy.

We investigated whether the neurodevelopmental delay was persistent or not among the 48 infants who were administered 
Table 1. Results of the Korean Developmental Screening Test at Each Follow-up Period

\begin{tabular}{|c|c|c|c|c|c|c|}
\hline Development level & Gross motor & Fine motor & Cognition & Communication & Social interaction & Self-control* \\
\hline \multicolumn{7}{|l|}{1 st FU (n=113) } \\
\hline Further evaluation & $1(0.9)$ & $6(5.3)$ & $3(2.7)$ & $6(5.4)$ & $5(4.4)$ & $1(1.2)$ \\
\hline Follow-up test & $22(19.5)$ & $20(17.7)$ & $21(18.6)$ & $24(21.2)$ & $24(21.2)$ & $18(21.2)$ \\
\hline Peer-level & $71(62.8)$ & $66(58.4)$ & $71(62.8)$ & $70(61.9)$ & $67(59.3)$ & $50(58.8)$ \\
\hline High-level & $19(16.8)$ & $21(18.6)$ & $18(15.9)$ & $13(11.5)$ & $17(15.0)$ & $16(18.8)$ \\
\hline \multicolumn{7}{|l|}{ 2nd FU (n=54) } \\
\hline Further evaluation & $3(5.6)$ & $3(5.6)$ & $5(9.3)$ & $3(5.6)$ & $4(7.4)$ & $5(9.3)$ \\
\hline Follow-up test & $11(20.4)$ & $13(24.1)$ & $5(9.3)$ & $9(16.7)$ & $11(20.4)$ & $8(14.8)$ \\
\hline Peer-level & $28(51.9)$ & $26(48.1)$ & $34(63.0)$ & $32(59.3)$ & $29(53.7)$ & $32(59.3)$ \\
\hline High-level & $12(22.2)$ & $12(22.2)$ & $10(18.5)$ & $10(18.5)$ & $10(18.5)$ & $9(16.7)$ \\
\hline
\end{tabular}

Values are expressed as number (\%).

*Different number of patients in 'self-control' section due to absence of 'self-control' section in the 16th-17th month questionnaire (n=85).

Abbreviation: FU, follow-up.

Table 2. Frequencies of Persistent Neurodevelopmental Delay

\begin{tabular}{|c|c|c|c|c|c|c|}
\hline 1st-2nd follow-up & $\begin{array}{l}\text { Gross motor } \\
\quad(n=48)\end{array}$ & $\begin{array}{l}\text { Fine motor } \\
\qquad(\mathrm{n}=48)\end{array}$ & $\begin{array}{c}\text { Cognition } \\
(n=48)\end{array}$ & $\begin{array}{c}\text { Communication } \\
(\mathrm{n}=48)\end{array}$ & $\begin{array}{l}\text { Social interaction } \\
\qquad(\mathrm{n}=48)\end{array}$ & $\begin{array}{c}\text { Self-control } \\
(\mathrm{n}=41)\end{array}$ \\
\hline Normal to normal & $28(58.3)$ & $28(58.3)$ & $36(75.0)$ & $31(64.6)$ & $30(62.5)$ & $27(65.9)$ \\
\hline Normal to delayed & $5(10.4)$ & $7(14.6)$ & $3(6.3)$ & $4(8.3)$ & $5(10.4)$ & $5(12.2)$ \\
\hline Delayed to normal & $9(18.8)$ & $7(14.6)$ & $4(8.3)$ & $7(14.6)$ & $6(12.5)$ & $6(14.6)$ \\
\hline Delayed to delayed & $6(12.5)$ & $6(12.5)$ & $5(10.4)$ & $6(12.5)$ & $7(14.6)$ & $3(7.3)$ \\
\hline
\end{tabular}

Values are expressed as number (\%).

the K-DST both in the first and second follow-up periods. A total of $7.3 \%$ to $14.6 \%$ of the infants showed persistent delay in each section(Table2). The highest proportion of infants with persistent delay was associated with the social interaction section (14.6\%) followed by the gross motor, fine motor, and communication sections (12.5\% each) of the K-DST. Two infants with persistent delay were eventually diagnosed with muscular dystrophy and one infant was diagnosed with tuberous sclerosis.

\section{Risk factors for delayed development}

The perinatal characteristics were analyzed as risk factors for delayed development, and the analysis was performed for each section. During the first follow-up period, male sex was a significant risk factor for delayed development in the cognition, communication, and social interaction sections. In addition, younger maternal age was a significant risk factor for delayed development in the fine motor and cognition sections (Table 3). During the second follow-up period, male MLPT infants were at a significantly higher risk of belonging to the delayed group in the communication section (Table 4). Moreover, a longer duration of oxygen therapy was associated with an increased risk of being categorized into the "further evaluation" group in the gross motor section (Table 5). None of the infants were diagnosed with bronchopulmonary dysplasia, necrotizing enterocolitis above stage II in the modified Bell's criteria, intraventricular hemorrhage above grade II, and retinopathy of prematurity. The other characteristics showed no significant association with the neurodevelopmental outcomes.

We also analyzed the risk factors and compared them between the normal group and the delayed group with delayed develop ment in more than two sections. No significant differences in the factors were found between the groups, even in the analysis of the normal group and the delayed group with delayed development in more than three sections.

\section{DISCUSSION}

Thefrequency ofneurodevelopmental delayin the MLPTinfants in our study was higher than that in the general infant population. In the K-DST, the cutoff value separating the "further evaluation" and "follow-up test required" categories was 2 standard deviations 
Table 3. Neonatal Outcomes of the Delayed Group and the Normal Group at the First Follow-up Period

\begin{tabular}{|c|c|c|c|}
\hline Variable & Delayed & Normal & $P$-value \\
\hline \multicolumn{4}{|l|}{ Gross motor } \\
\hline No. of patients & 24 & 89 & \\
\hline Male sex & $10(41.7)$ & $50(56.2)$ & 0.252 \\
\hline Maternal age (yr) & $33.63 \pm 4.41$ & $33.13 \pm 4.27$ & 0.621 \\
\hline \multicolumn{4}{|l|}{ Fine motor } \\
\hline No. of patients & 26 & 87 & \\
\hline Male sex & $17(65.4)$ & $43(49.4)$ & 0.183 \\
\hline Maternal age (yr) & $30.81 \pm 4.31$ & $33.97 \pm 4.02$ & $0.001^{*}$ \\
\hline \multicolumn{4}{|l|}{ Cognition } \\
\hline No. of patients & 24 & 89 & \\
\hline Male sex & $19(79.2)$ & $41(46.1)$ & $0.005^{*}$ \\
\hline Maternal age (yr) & $31.67 \pm 5.19$ & $33.66 \pm 3.93$ & $0.042^{*}$ \\
\hline \multicolumn{4}{|l|}{ Communication } \\
\hline No. of patients & 30 & 83 & \\
\hline Male sex & $24(80.0)$ & $36(43.4)$ & $0.001^{*}$ \\
\hline Maternal age (yr) & $32.37 \pm 4.08$ & $33.55 \pm 4.33$ & 0.194 \\
\hline \multicolumn{4}{|l|}{ Social interaction } \\
\hline No. of patients & 29 & 84 & \\
\hline Male sex & $22(75.9)$ & $38(45.2)$ & $0.005^{*}$ \\
\hline Maternal age (yr) & $32.62 \pm 4.88$ & $33.45 \pm 4.07$ & 0.370 \\
\hline \multicolumn{4}{|l|}{ Self-control } \\
\hline No. of patients & 19 & 67 & \\
\hline Male sex & $11(57.9)$ & $36(53.7)$ & 0.799 \\
\hline Maternal age (yr) & $33.56 \pm 4.19$ & $32.42 \pm 4.10$ & 0.182 \\
\hline
\end{tabular}

Values are expressed as number (\%) or mean \pm standard deviation. ${ }^{*} P<0.05$.

below the mean score, and the cutoff value separating the "followup test required" and "peer level" categories was 1 standard deviation below the mean score ${ }^{8)}$. Accordingly, the rate of "further evaluation" and "follow-up test required" results was not expected to be higher than $3 \%$ and $14 \%$, respectively. However, in nearly all sections of the test in our study, the proportion of MLPT infants categorized into the "further evaluation" and "follow-up test re quired" groups was higher than $3 \%$ and $14 \%$, respectively ${ }^{15)}$. These results correspond with those of previous studies from other countries that concluded that MLPT infants have a higher risk for neurodevelopmental delay than term infants ${ }^{3,4)}$. In longterm follow-up studies that evaluated preschool- or school-aged children born as MLPT infants, the academic performance and cognitive scores were lower in MLPT infants than in their full-term counterparts $^{16-19)}$. In our study, $>10 \%$ of the MLPT infants showed persistent neurodevelopmental delay in both follow-up periods
Table 4. Neonatal Outcomes of the Delayed Group and the Normal Group at the Second Follow-up Period

\begin{tabular}{lccc}
\hline Variable & Delayed & Normal & $P$-value \\
\hline Gross motor & & & \\
No. of patients & 14 & 40 & \\
Male sex & $5(35.7)$ & $17(42.5)$ & 0.453 \\
Fine motor & & & \\
No. of patients & 16 & 38 & \\
Male sex & $8(50.0)$ & $14(36.8)$ & 0.275 \\
Cognition & & & \\
No. of patients & 10 & 44 & 0.155 \\
Male sex & $6(60.0)$ & $16(36.4)$ & \\
Communication & & & \\
No. of patients & 12 & 42 & $0.042^{*}$ \\
Male sex & $8(66.7)$ & $14(33.3)$ & \\
Social interaction & & & \\
No. of patients & 15 & 39 & 0.402 \\
Male sex & $7(46.7)$ & $15(38.5)$ & \\
Self-control & & $15(36.6)$ & 0.217 \\
No. of patients & 13 & & \\
Male sex & $7(53.8)$ & 41 & \\
\hline
\end{tabular}

Values are expressed as number (\%).

${ }^{*} P<0.05$.

in all sections except for the self-control section. Moreover, two infants had a neurological disease. Therefore, the K-DST is an appropriate method for assessing the neural development of MLPT infants, detecting early neurodevelopmental delay, and guiding the appropriate intervention .

Many reports have shown that the incidence of neurodevelop mental disorders increases as the gestational age decreases, mainly in VLBW infants ${ }^{20-23)}$. A number of reports also contend that the second half of pregnancy is crucial in neurodevelopment. This is because brain development is accelerated in this period and the interruption of normal brain development can lead to irreversible changes in brain structure ${ }^{24,25)}$. However, no significant association between gestational age and developmental delay was observed in our study. Further studies are needed to evaluate the relationship between gestational age and neurodevelopmental delay in MLPT infants.

The risk factors for neurodevelopmental delay in our study were male sex, prolonged oxygen therapy during admission, and younger maternal age. Male sex has been suggested as a risk factor for unfavorable neurodevelopmental outcomes in previous studies ${ }^{26,27)}$, although few proven mechanisms for this predominance were suggested. In addition, many of these stud- 
Table 5. Neonatal Outcomes of the "Further Evaluation" Group and the Normal Group at the Second Follow-up Period

\begin{tabular}{|c|c|c|c|}
\hline Variable & $\begin{array}{l}\text { Further } \\
\text { evaluation }\end{array}$ & Normal & $P$-value \\
\hline \multicolumn{4}{|l|}{ Gross motor } \\
\hline No. of patients & 3 & 40 & \\
\hline Duration of oxygen therapy (d) & $8.00 \pm 8.54$ & $2.58 \pm 3.84$ & $0.036^{*}$ \\
\hline Surfactant therapy & 0 & $3(7.5)$ & 0.801 \\
\hline \multicolumn{4}{|l|}{ Fine motor } \\
\hline No. of patients & 3 & 38 & \\
\hline Duration of oxygen therapy (d) & $5.67 \pm 9.82$ & $2.58 \pm 3.76$ & 0.236 \\
\hline Surfactant therapy & 0 & $3(7.9)$ & 0.791 \\
\hline \multicolumn{4}{|l|}{ Cognition } \\
\hline No. of patients & 5 & 44 & \\
\hline Duration of oxygen therapy (d) & $5.20 \pm 7.66$ & $2.23 \pm 3.60$ & 0.131 \\
\hline Surfactant therapy & 0 & $2(4.5)$ & 0.804 \\
\hline \multicolumn{4}{|l|}{ Communication } \\
\hline No. of patients & 3 & 42 & \\
\hline Duration of oxygen therapy (d) & $5.67 \pm 9.82$ & $2.45 \pm 3.72$ & 0.207 \\
\hline Surfactant therapy & $1(33.3)$ & $6(14.2)$ & 0.464 \\
\hline \multicolumn{4}{|l|}{ Social interaction } \\
\hline No. of patients & 4 & 39 & \\
\hline Duration of oxygen therapy (d) & $4.25 \pm 8.50$ & $2.69 \pm 3.77$ & 0.494 \\
\hline Surfactant therapy & 0 & $3(7.7)$ & 0.741 \\
\hline \multicolumn{4}{|l|}{ Self-control } \\
\hline No. of patients & 5 & 41 & \\
\hline Duration of oxygen therapy (d) & $3.40 \pm 7.60$ & $2.61 \pm 3.79$ & 0.699 \\
\hline Surfactant therapy & 0 & $2(4.9)$ & 0.792 \\
\hline
\end{tabular}

Values are expressed as mean \pm standard deviation or number (\%). ${ }^{*} P<0.05$.

ies mainly focused on VLBW infants. This male disadvantage seems to also be applicable to MLPT infants. Prolonged oxygen therapy was not reported as a single independent risk factor for neurodevelopmental delay in preterm infants, although there have been many studies on the relationship between bronch opulmonary dysplasia and neurodevelopmental delay. Previous studies observed that neurodevelopmental outcomes were in dependent of bronchopulmonary dysplasia, contrary to the results of other prior studies ${ }^{28-32)}$. Given that no infant was diag. nosed with bronchopulmonary dysplasia in our study, prolong. ed oxygen therapy itself can be an independent risk factor for neurodevelopmental delay even without a diagnosis of bronchopulmonary dysplasia. Recent studies on the association be tween maternal age and neurodevelopmental outcomes showed that increased maternal age is not associated with unfavorable neurodevelopmental outcomes ${ }^{33,34)}$.
In a further investigation among infants with normal results in the first K-DST, we analyzed the difference between infants with normal development and those who had delayed development in the second K-DST. Intraventricular hemorrhage (42.9\% in the delayed group and $7.1 \%$ in the normal group, $P=0.044$ ) was identified as a significant risk factor for delayed development in the fine motor section. This suggests that close observation and serial evaluation are needed for infants with intraventricular hemorrhage. However, further studies are needed to evaluate the relationship between the severity of intraventricular hemorrhage and neurodevelopmental delay in MLPT infants because all infants in our study had grade I intraventricular hemorrhage.

A strength of this study is that it analyzed MLPT infants in Korea and can thus contribute to new knowledge about this infant population. Most of the MLPT infants in Korea do not re ceive appropriate follow-up care after discharge from the NICU. Accordingly, few studies have investigated the correlation between MLPT birth and neural development. Another strength of this study is the use of the K-DST. Unlike other tests, the K-DST can provide the examiner with serial developmental data of one infant. Thus, the K-DST is suitable for follow-up studies for observing the changes in the developmental stage of one infant. The limitation of this study was its retrospective design. Because of the retrospective nature, the timing of follow-ups after dis charge from the NICU considerably varied among the MLPT infants in this study. Therefore, comparing neurodevelopmental outcomes between different infants and within one infant was difficult. As a result, many infants were excluded from the study. In addition, among 385 infants admitted to the NICU during the study period, 231 infants were excluded owing to loss to followup. Further, among 113 infants who were administered the first K-DST, 65 infants were not administered the second K-DST. Thus, a selection bias might exist in this study. Finally, this study was conducted at a single center, which means that the number of analyzed infants was not sufficient for reaching a definitive conclusion.

In conclusion, the neurodevelopmental outcomes of MLPT infants assessed with the K-DST were unfavorable relative to the general infant population. The risk factors of neurodevelopmental delay were male sex, prolonged oxygen therapy during NICU admission, and younger maternal age. These findings highlight the need for a close observation of infants with these charac teristics. In addition, for children born as MLPT infants in Korea, serial evaluation using the K-DST from an early stage of develop 
ment is recommended. Furthermore, large-scale future studies on the neurodevelopmental outcomes of MLPT infants in Korea are required.

\section{ARTICLE INFORMATION}

\section{Ethical statement}

The study was approved by the Institutional Review Board of Korea University Anam Hospital (approval number: 2019 AN0260). This study was exempted from Informed consent by Institutional Review Board of Korea University Anam Hospital.

\section{Conflicts of interest}

No potential conflict of interest relevant to this article was reported.

\section{Author contributions}

Conception or design: Y.S.N., E.H.L.

Acquisition, analysis, or interpretation of data: Y.S.N.

Drafting the work or revising: Y.S.N., J.S.H., J.H.B., E.H.L.

Final approval of the manuscript: E.H.L., J.S.H., J.H.B., E.H.L.

\section{ORCID}

Yun Sung Nam https://orcid.org/0000-0001-8546-3466

Eun Hee Lee https://orcid.org/0000-0002-1539-8184

\section{Acknowledgments}

None

\section{REFERENCES}

1. Raju TN, Higgins RD, Stark AR, Leveno KJ. Optimizing care and outcome for late-preterm (near-term) infants: a summary of the workshop sponsored by the National Institute of Child Health and Human Development. Pediatrics 2006;118:1207-14.

2. March of Dimes Birth Defects Foundation; World Health Organization; Partnership for Maternal, Newborn \& Child Health; Save the Children. Born too soon: the global action report on preterm birth. Geneva: World Health Organization, 2012.

3. Cheong JL, Doyle LW, Burnett AC, Lee KJ, Walsh JM, Potter CR, et al. Association between moderate and late preterm birth and neurodevelopment and social-emotional development at age 2 years. JAMA Pediatr 2017;171:e164805.
4. Johnson S, Matthews R, Draper ES, Field DJ, Manktelow BN, Marlow N, et al. Early emergence of delayed social competence in infants born late and moderately preterm. J Dev Behav Pediatr 2015;36:690-9.

5. Tomashek KM, Shapiro-Mendoza CK, Davidoff MJ, Petrini JR. Differences in mortality between late-preterm and term singleton infants in the United States, 1995-2002. J Pediatr 2007; 151:450-6.

6. Ohgi S, Fukuda M, Akiyama T, Gima H. Effect of an early inter vention programme on low birthweight infants with cerebral injuries. J Paediatr Child Health 2004;40:689-95.

7. Resnick MB, Armstrong S, Carter RL. Developmental interven tion program for high-risk premature infants: effects on development and parent-infant interactions. J Dev Behav Pediatr 1988;9:73-8.

8. Korea Centers for Disease Control and Prevention. Koreandevelopment screening test for infants and children. Cheongju: Korea Centers for Disease Control and Prevention, 2014.

9. Yim CH, Kim GH, Eun BL. Usefulness of the Korean Develop mental Screening Test for infants and children for the evaluation of developmental delay in Korean infants and children: a singlecenter study. Korean J Pediatr 2017;60:312-9.

10. Pascal A, Govaert P, Oostra A, Naulaers G, Ortibus E, Van den Broeck C. Neurodevelopmental outcome in very preterm and very-low-birthweight infants born over the past decade: a metaanalytic review. Dev Med Child Neurol 2018;60:342-55.

11. World Health Organization. ICD-10: international statistical classification of diseases and related health problems: tenth revision. 2nd ed. Geneva:WHO, 2004.

12. Sung IK, Vohr B, Oh W. Growth and neurodevelopmental out come of very low birth weight infants with intrauterine growth retardation: comparison with control subjects matched by birth weight and gestational age. J Pediatr 1993;123:618-24.

13. Vohr BR, Wright LL, Poole WK, McDonald SA. Neurodevelop. mental outcomes of extremely low birth weight infants $<32$ weeks' gestation between 1993 and 1998. Pediatrics 2005;116: 635-43.

14. Jin JH, Yoon SW, Song J, Kim SW, Chung HJ. Long-term cog. nitive, executive, and behavioral outcomes of moderate and late preterm at school age. Clin Exp Pediatr 2020;63:219-25.

15. Suh CR, Sohn SY, Kim GH, Jung SK, Eun BL. Single-center experience of the Korean-Developmental Screening Test for infants and children. Korean J Pediatr 2016;59:483-49.

16. Chan E, Leong P, Malouf R, Quigley MA. Long-term cognitive and school outcomes of late-preterm and early-term births: a systematic review. Child Care Health Dev 2016;42:297-312.

17. Chyi LJ, Lee HC, Hintz SR, Gould JB, Sutcliffe TL. School outcomes of late preterm infants: special needs and challenges for infants born at 32 to 36 weeks gestation. J Pediatr 2008;153:2531. 
18. Johnson S, Evans TA, Draper ES, Field DJ, Manktelow BN, Marlow N, et al. Neurodevelopmental outcomes following late and moderate prematurity: a population-based cohort study. Arch Dis Child Fetal Neonatal Ed 2015;100:F301-8.

19. Petrini JR, Dias T, McCormick MC, Massolo ML, Green NS, Escobar GJ. Increased risk of adverse neurological development for late preterm infants. J Pediatr 2009;154:169-76.

20. Gargus RA, Vohr BR, Tyson JE, High P, Higgins RD, Wrage LA, et al. Unimpaired outcomes for extremely low birth weight infants at 18 to 22 months. Pediatrics 2009;124:112-21.

21. Hirvonen M, Ojala R, Korhonen P, Haataja P, Eriksson K, Gissler $\mathrm{M}$, et al. Visual and hearing impairments after preterm birth. Pediatrics 2018;142:e20173888.

22. Leversen KT, Sommerfelt K, Ronnestad A, Kaaresen PI, Farstad T, Skranes J, et al. Prediction of neurodevelopmental and sensory outcome at 5 years in Norwegian children born extremely preterm. Pediatrics 2011;127:e630-8.

23. Serenius F, Kallen K, Blennow M, Ewald U, Fellman V, Holmstrom G, et al. Neurodevelopmental outcome in extremely preterm infants at 2.5 years after active perinatal care in Sweden. JAMA 2013;309:1810-20.

24. Guihard-Costa AM, Larroche JC. Differential growth between the fetal brain and its infratentorial part. Early Hum Dev 1990; 23:27-40.

25. Kapellou O, Counsell SJ, Kennea N, Dyet L, Saeed N, Stark J, et al. Abnormal cortical development after premature birth shown by altered allometric scaling of brain growth. PLoS Med 2006;3:e265.

26. Hintz SR, Kendrick DE, Vohr BR, Kenneth Poole W, Higgins RD; Nichd Neonatal Research Network. Gender differences in neurodevelopmental outcomes among extremely preterm, ex- tremely-low-birthweight infants. Acta Paediatr 2006;95:1239-48.

27. Reiss AL, Kesler SR, Vohr B, Duncan CC, Katz KH, Pajot S, et al. Sex differences in cerebral volumes of 8-year-olds born preterm. J Pediatr 2004;145:242-9.

28. Anderson PJ, Doyle LW. Neurodevelopmental outcome of bronchopulmonary dysplasia. Semin Perinatol 2006;30:227-32.

29. Ehrenkranz RA, Walsh MC, Vohr BR, Jobe AH, Wright LL, Fanaroff AA, et al. Validation of the National Institutes of Health consensus definition of bronchopulmonary dysplasia. Pediatrics 2005;116:1353-60.

30. Hintz SR, Kendrick DE, Vohr BR, Poole WK, Higgins RD; National Institute of Child Health and Human Development Neonatal Research Network. Changes in neurodevelopmental outcomes at 18 to 22 months' corrected age among infants of less than 25 weeks' gestational age born in 1993-1999. Pediatrics 2005;115:1645-51.

31. Natarajan G, Pappas A, Shankaran S, Kendrick DE, Das A, Higgins $\mathrm{RD}$, et al. Outcomes of extremely low birth weight infants with bronchopulmonary dysplasia: impact of the physiologic definition. Early Hum Dev 2012;88:509-15.

32. Trittmann JK, Nelin LD, Klebanoff MA. Bronchopulmonary dysplasia and neurodevelopmental outcome in extremely preterm neonates. Eur J Pediatr 2013;172:1173-80.

33. Vohr BR, Tyson JE, Wright LL, Perritt RL, Li L, Poole WK, et al. Maternal age, multiple birth, and extremely low birth weight infants. J Pediatr 2009;154:498-503.

34. DiLabio J, Zwicker JG, Sherlock R, Daspal S, Shah PS, Shah V, et al. Maternal age and long-term neurodevelopmental outcomes of preterm infants $<29$ weeks gestational age. J Perinatol 2020 Jul 21 [Epub]. https://doi.org/10.1038/s41372-020-0735-9. 